\title{
Amlodipine and Atorvastatin Improved Hypertensive Cardiac Remodeling through Regulation of MMPs/TIMPs in SHR Rats
}

\author{
Jingchao Lu Jie Hao Hong Du Bing Xiao Yue Li Xiuchun Yang Wei Cui
}

Department of Cardiology, The Second Hospital of Hebei Medical University, Shijiazhuang City, China

\section{Key Words}

Matrix metalloproteinases - Tissue inhibitors of matrix metalloproteinases - Amlodipine • Atorvastatin • Cardiac hypertrophy $\cdot$ Spontaneous hypertension

\begin{abstract}
Background: MMPs/TIMPs system is well known to play important roles in pressure overloadinduced cardiac remodeling, and Amlodipine and Atorvastatin have been showed to exert favourable protective effects on cardiovascular disease, however, it is not clear whether Amlodipine and Atorvastatin can improve hypertensive cardiac remodeling and whether the MMPs/TIMPs system is involved. The present study aims to answer these questions. Methods: 36 weeks old male spontaneous hypertension (SHR) rats were randomly divided into four groups: 1). SHR control group, 2). Amlodipine alone (10 mg/kg/d) group, 3). Atorvastatin alone $(10 \mathrm{mg} / \mathrm{kg} / \mathrm{d})$ group, 4).Combination of Amlodipine and Atorvastatin $(10 \mathrm{mg} / \mathrm{kg} / \mathrm{d}$ for each) group. Same gender, weight and age of Wistar-Kyoto (WKY) rats with normal blood pressure were used as normal control. Drugs were administered by oral gavage over 12 weeks. The blood pressure and left ventricle mass index were measured. Enzyme activity of MMP-2 and MMP-9 was assessed with Gelatin zymography. MMP-2, MMP-9, TIMP-1 and TIMP-2 mRNA and protein expression was studied by RT-PCR and Western blot. Single factor ANOVA and LSD-t test were used in statistical analysis. Results: Treatment with Amlodipine alone or combination with atorvastatin significantly decreased blood pressure, left ventricle mass index in SHR rats $(P<0.05$ for both). Compared with WKY rats, the myocardial levels of MMP-2, MMP-9 mRNA, protein and enzyme activity were significantly increased $(P<0.05)$. Amlodipine alone, Atorvastatin alone, and combination of the two all reduced MMP-2 and MMP-9 mRNA, protein and enzyme activity, with the best effects seen in the combination. Compared with WKY rats, the myocardial levels of TIMP-1 mRNA and protein were significantly increased $(P<0.05)$, however, there was no difference in levels of TIMP-2. Neither Amlodipine alone, Atorvastatin alone, nor combination of the two drugs significantly affect the expression of TIMP-1 or TIMP2. Conclusion: Amlodipine and Atorvastatin could improve ventricular remodeling in SHR rats through intervention with the imbalance of MMP-2/TIMP-2 and MMP-9/TIMP-1 system.
\end{abstract}




\section{Introduction}

Myocardial tissue is mainly composed of cardiomyocytes and extracellular matrix (ECM). ECM includes collagen, proteoglycans, glycoproteins, glycosaminoglycans and elastin fibers. ECM is not only the scaffold to maintain cardiac structure, to maintain the normal alignment of cardiomyocytes and muscle fibers through integrating the geometry of collagen-integrincytoskeleton-muscle fiber, it is also the dynamic microenvironment for extracellular signal transduction. ECM remodeling is mainly characterized as fibrosis of myocardial interstitium and surrounding small blood vessels, and it has been considered a key step in the evolution of heart failure, as well as an important pathological features of hypertensive left ventricular remodeling [1]. ECM is mainly degraded by matrix metalloproteinases (MMPs), and MMPs were regulated by tissue inhibitor of matrix metalloproteinase (TIMPs), therefore ECM remodeling is closely related to the changes in balance of MMPs/TIMPs.

MMPs are a class of $\mathrm{Zn}^{2+}$ dependent endopeptidase family that specifically degrade ECM. In the more than 20 known species of matrix metalloproteinases, more and more research showed that enhanced gelatinase (MMP-2 and MMP-9) expression and activity play an important role in pressure overload-induced cardiac matrix remodeling [2-6]. Our previous study has shown that reactive oxygen species (ROS) and inflammatory factors were upregulated in elderly SHR myocardial tissue [7]. Since MMP-2 and MMP-9 are the downstream factors of ROS, inflammatory cytokines TNF- $\alpha$ and IL-1 $\beta$, we hypothesized that the expression and activity of MMP-2 and MMP-9 may also be enhanced in the cardiac tissues of elderly SHR rats and they may participate in the regulation of cardiac matrix remodeling and promote cardiac interstitial fibrosis.

Based on the role of MMP-2 and MMP-9 in hypertensive left ventricular remodeling, intervention on their upstream factors such as activated renin-angiotensin system, oxidative stress and inflammatory cytokines, or design of specific MMP inhibitors have become the hop topics for research in prevention and treatment of hypertensive left ventricular remodeling [8-10]. In vitro studies have found that Amlodipine can reduce MMP-2 expression in cardiac fibroblast [11], Pravastatin on the other hand, could reduce the expression of MMP-2, MMP9, TIMP-1 and TIMP- 2 in myocardial tissues of salt-sensitive hypertensive rats and improve cardiac hypertrophy and cardiac function $[12,13]$. Accordingly, we hypothesized that the combination of Amlodipine and Atorvastatin may improve cardiac matrix remodeling by intervention with MMPs / TIMPs system in spontaneously hypertensive rats.

In this study, we aim to study the expression of MMP-2, MMP-9, TIMP-1 and TIMP-2 in myocardial tissue in SHR rats, and to explore the effects of Amlodipine and Atorvastatin monotherapy and combination therapy on expression and activity of MMP-2, MMP-9, TIMP1 and TIMP-2 and to provide experimental evidence for treatment of hypertensive left ventricular remodeling with Amlodipine and Atorvastatin combination therapy.

\section{Materials and Methods}

\section{Animals}

The male WKY rats used in this study were purchased from Chinese Academy of Sciences Shanghai Experimental Animal Center at 16 weeks of age, body weight (332 \pm s 18) g, and clean grade with certificate: SCXK (Shanghai) 2003-0003. The male SHR rats used in this study were purchased from Beijing Wei Tong Lihua Experimental Animal Center at 16 weeks of age, body weight $(325 \pm 20) \mathrm{g}$, and clean grade with certificate: SCXK (Beijing) 2007-2001. WKY rats and SHR rats were hosted till 36 weeks old for experiment in clean level environment, with light/dark cycle $12 / 12 \mathrm{~h}$, a relative humidity of $50 \%$ to $60 \%$, the ambient temperature $22 \sim 25^{\circ} \mathrm{C}, 4 \sim 5$ rats per cage, free access to food and water. All procedures were approved by the Animal Care and Use Committee at Hebei Medical University. 


\section{Cellular Physiology Cell Physiol Biochem 2016;39:47-60 and Biochemistry Published online: June 20, $2016 \quad \begin{aligned} & \text { DOI: 10.1159/000445604 } 2016 \text { The Author(s). Published by S. Karger AG, Basel } \\ & \text { www.karger.com/cpb }\end{aligned}$}

Lu et al.: Amlodipine and Atorvastatin Improved Hypertensive Cardiac Remodeling

\section{Experimental reagents}

Amlodipine and Atorvastatin were from Pfizer Inc. USA. Trizol was from Invitrogen Inc. USA. DEPC and PCR primers were from Beijing Parkson Gene Technology Ltd, China. dNTP, MMLV reverse transcriptase and random hexamer were from Promega Inc. USA. Rnasin, Taq DNA polymerase, and DNA ladder were from Sino-American Inc, Beijing, China. Rabbit anti-MMP-2 polyclonal antibody, rabbit anti-TIMP-1 polyclonal antibody, rabbit anti-TIMP-2 polyclonal antibody, goat anti-MMP-9 polyclonal antibody were from Santa Cruz Inc. USA.

\section{Grouping and treatment of the experimental animals}

36 weeks old male spontaneous hypertension (SHR) rats were randomly divided into four groups: 1). SHR control group: rats; 2). Amlodipine alone (10 mg/kg/d) group: 16 rats; 3). Atorvastatin alone (10 mg/ $\mathrm{kg} / \mathrm{d}$ ) group: 16rats; 4). Combination of Amlodipine and Atorvastatin (10 mg/kg/d for each) group: 18 rats. 14 WKY rats with normal blood pressure were used as normal control. Drugs were crashed, dissolved in water and administered by oral gavage over 12 weeks for experimental groups [14]. Same volume of water was administered by oral gavage over 12 weeks for control groups.

\section{Measurement of blood pressure}

In all rats, systolic blood pressure (SBP) was measured non-invasively using the tail-cuff method (LE 5001; PanLab, Barcelona, Spain). The SBP values reported are the average of three sequential blood pressure measurements that were within $10 \mathrm{mmHg}$ of each other.

\section{Echocardiographic study}

Rats were anaesthetized with sodium pentobarbital ( $40 \mathrm{mg} / \mathrm{kg}$, i.p.). Transthoracic echocardiography was performed using a commercially available Acuson Ultrasound System (Sequoia 512; Siemens, Erlangen, Germany) equipped with a $14 \mathrm{MHz}$ linear transducer, as described previously [6]. The following parameters were measured: left ventricular (LV) end-diastolic dimension (LVEDd), LV end-systolic dimension (LVEDs), LV posterior wall thickness at diastole (LVPWd), interventricular septal thickness at diastole (IVSd), percentage of LV fractional shortening (LVSF) and LV ejection fraction (LVEF). The LV weight (LVW) was calculated as follows: $($ LVW $)=1.04 \times\left[(\text { IVS }+ \text { LVEDd }+ \text { LVPWd })^{3}-(\text { LVEDd })^{3}\right]$, LV relative wall thickness $($ RWT $)=2 \times$ LVPWd / LVEDd. Both LVEF and LVSF were used as indices of cardiac systolic function, whereas isovolumic relaxation time (IVRT) and early and late diastolic mitral inflow velocities (E wave and A wave), $\mathrm{E} / \mathrm{A}$ ratio was used as an index of diastolic function. A joint assessment of diastolic and systolic LV function was performed by the myocardial performance index (Tei index). All LV structures and function were manually measured by the same observer.

\section{Measurement of left ventricular mass index}

After the weight of rat was measured, the chest of the rat was immediately open and the heart was quickly removed. After rinsing with ice saline, atrium and right ventricular free wall were cut along the atrioventricular ring. After dried with filter paper, the remaining septal and left ventricular free wall were weighed as left ventricular mass. Left ventricular mass index (LVMI) = left ventricular mass / body weight $(\mathrm{mg} / \mathrm{g})$. The left ventricle was cut perpendicular to the long axis, LV central section was harvested and fixed in $10 \%$ neutral formalin, and the remaining portion of the left ventricle was snap frozen in liquid nitrogen and then stored in $-80^{\circ} \mathrm{C}$ refrigerator.

\section{Tissue protein extraction}

Tissue protein extract. $100 \mathrm{mg}$ of cardiac tissue was homogenized in $1 \mathrm{ml}$ RIPA lysis buffer (150 $\mathrm{mmol} / \mathrm{L} \mathrm{NaCl}, 50 \mathrm{mmol} / \mathrm{L} \mathrm{pH} 7.8$ of Tris-HCl, $0.1 \% \mathrm{NP}-40,0.5 \%$ sodium deoxycholate, $0.1 \%$ SDS, $0.1 \%$ EDTA, $1 \mathrm{mmol} / \mathrm{L}$ PMSF, $1 \mathrm{mmol} / \mathrm{L}$ DTT) on ice bath. The homogenate was centrifuged at $4^{\circ} \mathrm{C}, 12000 \mathrm{rpm}$ for 10 $\mathrm{min}$, the supernatant was harvested as myocardial tissue total protein extract. Sample was aliquoted and stored at $-70^{\circ} \mathrm{C}$ for use. The protein content of the extract was measured using a modified Lowry method.

Zymography to study gelatinase MMP-2 and MMP-9 activity. PAGE: 8\% separating gel (containing $0.2 \%$ gelatin) and $5 \%$ stacking gel were prepared. Myocardial tissue protein extracts from rats in each group were mixed with $5 \times$ sample loading buffer $(0.1 \mathrm{mmol} / \mathrm{L}$ Tris- $\mathrm{HCl}, \mathrm{pH} 6.8,20 \%$ glycerol, $0.1 \%$ bromophenol blue, $4 \%$ SDS $)$ and were loaded into PAGE gel. The gel was run at $4^{\circ} \mathrm{C}$ with constant voltage $(120 \mathrm{v})$ for $2 \sim 2.5$ h (running buffer: $25 \mathrm{mmol} / \mathrm{L}$ Tris, $250 \mathrm{mmol} / \mathrm{L}$ glycine, 0.1\% SDS), when the bromophenol blue front moves to approximately $1 \mathrm{~cm}$ from the bottom of the gel, the electrophoresis was stopped. 


\section{Cellular Physiology Cell Physiol Biochem 2016;39:47-60

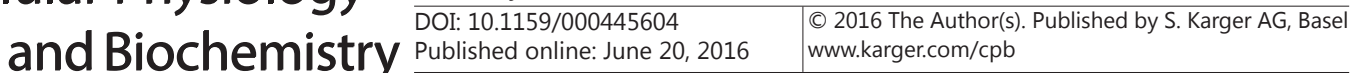

Lu et al.: Amlodipine and Atorvastatin Improved Hypertensive Cardiac Remodeling

Gelatin digestion reaction. After electrophoresis, the gel was rinsed by 2.5\% Triton X-100 twice for 15 min each to remove the SDS, so that gelatinase would refold; the rinse was discarded, then reaction buffer (50 mmol / L Tris-HCl, pH 8.0, $50 \mathrm{mmol} / \mathrm{L} \mathrm{NaCl}, 10 \mathrm{mmol} / \mathrm{L} \mathrm{CaCl}_{2}$ ) was added and incubated at $37^{\circ} \mathrm{C}$ for 9 $\mathrm{h}$, so that gelatinase could fully hydrolyzed the gelatin in gel.

Dyeing and bleaching. After the completion of the reaction, the reaction buffer was discarded, Coomassie blue staining buffer (0.25\% CBB R-250, 40\% methanol, 10\% acetic acid) was added and incubated for 2 $4 \mathrm{~h}$; the staining solution was then discarded, decolorizing solution ( $40 \%$ methanol, $10 \%$ acetic acid) was added and incubated for $2 \sim 4 \mathrm{~h}$, during which time destaining solution was replaced once, decolorization was stopped when white stripe was clear to a blue background. Quantity One V4.6.2 software (Bio-Rad Corporation, US) was used to perform quantitative analysis of signal intensity of the white stripe zone.

\section{Western blot}

All antibodies were purchased from Santa Cruz Biotechnology (CA, USA). Certain amount of protein samples were mixed with $5 \times$ SDS sample buffer $(0.1 \mathrm{mmol} / \mathrm{L} \mathrm{pH} 6.8$ of Tris- $\mathrm{HCl}, 20 \%$ glycerol, $0.1 \%$ bromophenol blue, $10 \% \beta$ - mercaptoethanol, $4 \%$ SDS) and boiled at $100^{\circ} \mathrm{C}$ for $5 \mathrm{~min}$ and then loaded onto $10 \%$ PAGE gel for electrophoresis. Protein sample was then transferred onto PVDF membrane, which was then incubated in 5\% skim milk in TTBS for two hours in room temperature. The PVDF membrane was then immersed with primary antibody diluted in TTBS $(10 \mathrm{mmol} / \mathrm{L}$ Tris- $\mathrm{HCl}, \mathrm{pH}$ 8.0, $150 \mathrm{mmol} / \mathrm{L} \mathrm{NaCl}, 0.05 \%$ Tween-20). The primary antibodies used were anti-MMP-2 antibody (1:400), anti-MMP-9 antibody (1:400), anti-TIMP-1 antibody (1:400), anti-TIMP-2 antibody (1:400). After overnight incubation with primary antibody, the membrane was washed three times with TTBS for $10 \mathrm{~min}$ each and then incubated with HRP conjugated secondary antibody for 2 hours. After washing with TTBS for 10 min three times, the membrane was then washed with TBS (10 mmol/L Tris- $\mathrm{HCl}, \mathrm{pH} 8.0,150 \mathrm{mmol} / \mathrm{L} \mathrm{NaCl}$ ) for $10 \mathrm{~min}$ once. The antigenantibody binding zone was detected by chemiluminescence. Quantity One V4.6.2 software (Bio-Rad, USA) was used to quantify the density of the Western blot band. $\beta$-actin was used as reference.

\section{RNA extraction, RT-PCR and real-time quantitative PCR}

RNA extraction. Total RNA was extracted from cardiac tissue in the different treatment groups using Invitrogen's Trizol one-step protocol according to Manufacturer's manual.

Reverse transcription (RT) reaction. $2 \mu \mathrm{g}$ total RNA was added into RT reaction system (AMV Buffer, dNTPs, Oligo dT Primer, AMV, RNAse Inhibitor, etc.) which was topped to $50 \mu$ with DEPC-treated water, centrifuge briefly after the mix, mineral oil was added onto the top of the reaction solution and was incubated in PCR machine at $42^{\circ} \mathrm{C}$ for 60 min (cDNA synthesis).

$R T$-PCR. $3 \mu \mathrm{l}$ reverse transcription product was used as template for PCR reaction, dNTPs (final concentration $0.2 \mathrm{mmol} / \mathrm{L}$ ), $\mathrm{MgCl}_{2} 2.5 \mathrm{mmol} / \mathrm{L}$, rat MMP-1, MMP-2, TIMP-1, TIMP-2or GAPDH primers(final concentration of $50 \mathrm{pmol} / \mathrm{L}$ ), $10 \times \mathrm{PCR}$ buffer, $2.5 \mu \mathrm{l}$, Taq DNA polymerase $2 \mathrm{U}$, sterile deionized water were added to the mixture accordingly to a total volume of $25 \mu \mathrm{l}$. The PCR reaction conditions were to $94^{\circ} \mathrm{C}$ for $2 \mathrm{~min}$ for initial denaturation, then $94^{\circ} \mathrm{C}$ for $40 \mathrm{~s}, 58^{\circ} \mathrm{C}$ for $50 \mathrm{~s}$ and $72^{\circ} \mathrm{C}$ for $90 \mathrm{~s}$, after 30 cycles, extension at $72^{\circ} \mathrm{C}$ for $10 \mathrm{~min}$. PCR amplification products were then loaded onto $1 \%$ agarose gel for electrophoresis. BIO -PROFIF gel image analysis system and Bio-1D ++ software were used for analyzing the electrophoresis results. GAPDH was used as a reference. All raw data were first normalized to internal control, and then normalized to normal control group which is WKY group. The primers were synthesized by Beijing Parkson Gene Technology Co. The primer sequences are as follows:

MMP-2: Upstream primer 5'- CTA TTC TGT CAG CAC TTT GG -3', Downstream primer 5'-CAG ACT TTG GTT CTC CAA CTT-3'.

MMP-9: Upstream primer 5'-TCG GTA TTG GAA GTT CTC GAA TCA CGG AGG-3', Downstream primer 5'-GGC ACT GCA GGA GGT CAT AGG TCA CGT A-3'.

TIMP-1: Upstream primer 5'-CCA CCT TAT ACC AGC GTT AGT-3', Downstream primer 5'-GGC ACT GCA GGA GGT CAT AGG TCA CGT A-3'.

TIMP-2: Upstream primer 5'-CCA AAG CAG TGA GCG AGA A-3', Downstream primer 5'-TTC CAG GGC ACA ATA AAG TC-3'.

GAPDH: Upstream primer 5'-CGC TAA CAT CAA ATG GGG TG-3', Downstream primer 5'- ACA ACC TGG TCC TCA GTG TA-3'. 
Lu et al.: Amlodipine and Atorvastatin Improved Hypertensive Cardiac Remodeling

Real-time quantitative PCR. The cDNA was subjected to real-time quantitative polymerase chain reaction (PCR) using Power SYBR Green PCR Master Mix (Applied Biosystems, Warrington, UK). Each realtime PCR reaction consisted of $2 \mathrm{uL}$ diluted reverse transcription (RT) product, $10 \mathrm{uL}$ SYBR Green PCR Master Mix and $250 \mathrm{nmol} / \mathrm{L}$ forward and reverse primers. Reactions were performed on a 7500 Real-Time PCR System (Applied Biosystems) for 40 cycles of $95^{\circ} \mathrm{C}$ for $15 \mathrm{~s}$ followed by $60^{\circ} \mathrm{C}$ for 1 min after an initial incubation at $95^{\circ} \mathrm{C}$ for $10 \mathrm{~min}$. The primers used for real-time PCR were as follows: type I collagen, forward 5'-TGC CGT GAC CTC AAG ATG TG-3' and reverse 5'-CAC AAG CGT GCT GTA GGT GA-3'; type III collagen mRNA, forward 5'-AGA TCA TGT CTT CAC TCA AGT C-3'and reverse 5'-TTT ACA TTG CCA TTG GCC TAG-3'. The fold change in expression of each gene was calculated using the $\Delta \Delta \mathrm{Ct}$ method, with the housekeeping gene GAPDH used as an internal control.

\section{Statistical analysis}

SPSS 11.0 software was used for statistical analysis. The experimental data were expressed as mean \pm standard deviation. Comparison between groups was performed using single factor ANOVA and LSD-t test. $\mathrm{P}<0.05$ was considered statistically different.

\section{Results}

\section{Changes of rat blood pressure}

The mean blood pressure of SHR rats was significantly higher than that of WKY rats $(221 \pm 6.2 \mathrm{mmHg}$ vs $125 \pm 7.1 \mathrm{mmHg}, \mathrm{P}<0.05)$. Atorvastatin treatment did not affect blood pressure $(220 \pm 7.6 \mathrm{mmHg}$ vs $221 \pm 6.2 \mathrm{mmHg}$, P > 0.05). Amlodipine alone or combination of Amlodipine and Atorvastatin treatment significantly decreased the blood pressure $(180 \pm 4.9 \mathrm{mmHg}$ vs $221 \pm 6.2 \mathrm{mmHg}, 178 \pm 5.8 \mathrm{mmHg}$ vs $221 \pm 6.2 \mathrm{mmHg}, \mathrm{P}<0.05$ for both comparisons), but there was no significant difference between Amlodipine alone or combination treatment groups $(180 \pm 4.9 \mathrm{mmHg}$ vs $178 \pm 5.8 \mathrm{mmHg}, \mathrm{P}>0.05)$ (Fig. 1).

\section{Changes in body weight, heart rate and LVMI}

There was no significant difference in body weight of rats in all groups $(P>0.05)$. The heart rate of SHR rats in both control and treatment groups were significantly higher than that of WKY control group $(\mathrm{P}<0.05)$, but heart rate between the groups of SHR rats was not significantly different $(\mathrm{P}>0.05)$. LVMI in SHR control group was significantly higher than that of WKY rats $(\mathrm{P}<0.05)$, after Amlodipine or (and) Atorvastatin treatment, LVMI was significantly decreased, with the best result shown in the combination treatment group $(\mathrm{P}<$ 0.05) (Table 1).

Fig. 1. Effects of Amlodipine, Atorvastatin, and their combination on blood pressure in SHR during 12 weeks treatment. Data are expressed as mean \pm SD $(n=10) .{ }^{*} P<0.05$ compared with SHR; ${ }^{*} P<0.05$ compared with SHR+AM+AT. SHR, SHR treated with vehicle; SHR+AM, SHR treated with Amlodipine; SHR+AT, SHR treated with Atorvastatin; SHR+AM+AT, SHR treated with Amlodipine and Atorvastatin.

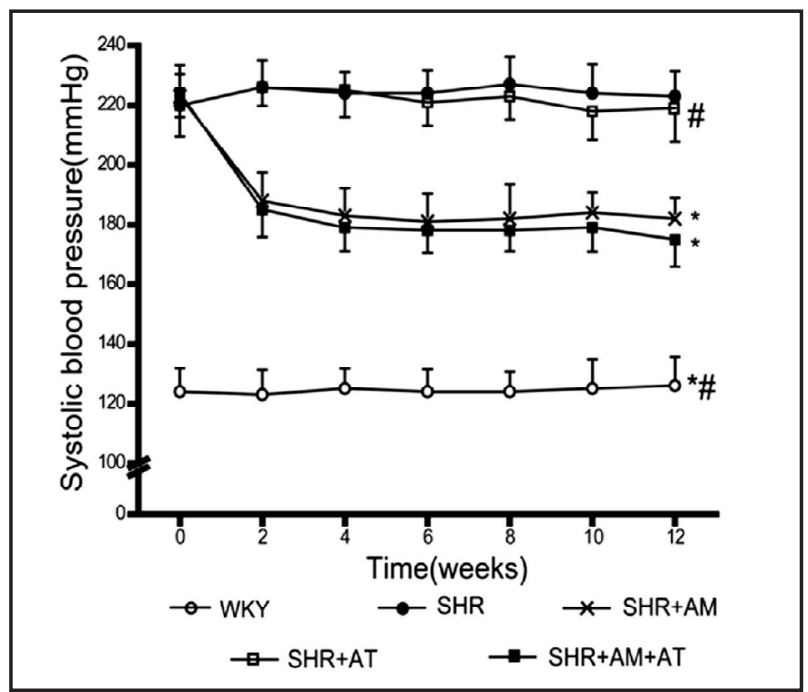


Table 1. Effects of amlodipine, atorvastatin, and their combination on weight, heart rate and LVMI in SHR rats $(\mathrm{n}=10, \pm \mathrm{s}) .{ }^{*} \mathrm{P}<0.05$ vs. SHR; \# $\mathrm{P}<0.05$ vs. SHR+AM+AT. BW: body weight; HR: heart rate; LVMI: left ventricle mass index. SHR: SHR treated with vehicle; SHR+AM: SHR treated with amlodipine; SHR+AT:SHR treated with atorvastatin; SHR+AM+AT: SHR treated with amlodipine and atorvastatin

\begin{tabular}{llllll}
\hline \multicolumn{1}{c}{ Groups } & \multicolumn{1}{c}{ WKY } & \multicolumn{1}{c}{ SHR } & SHR+AM & SHR+AT & SHR+AM+AT \\
\hline BW (g) & $387 \pm 30$ & $365 \pm 25$ & $359 \pm 18$ & $360 \pm 20$ & $358 \pm 24$ \\
HR(bpm) & $320 \pm 31^{* \#}$ & $371 \pm 17$ & $370 \pm 21$ & $361 \pm 40$ & $357 \pm 21$ \\
LVMI $(\mathrm{mg} / \mathrm{g})$ & $2.05 \pm 0.18^{* \#}$ & $3.01 \pm 0.21$ & $2.52 \pm 0.16^{* \#}$ & $2.69 \pm 0.12^{* \#}$ & $2.26 \pm 0.18^{*}$
\end{tabular}

Table 2. Effects of Amlodipine, Atorvastatin, and their combination on cardiac remodeling and cardiac function estimated by echocardiography of WKY and SHR ( $n=10, \pm$ s). * P< 0.05 vs. SHR; \# P 0.05 vs. SHR+AM+AT. LVESd, left ventricular (LV) systolic diameter; LVEDd, LV end-diastolic diameter; IVSd, end-diastolic thickness of the interventricular septum; LVPWd, end-diastolic thickness of the posterior wall; LVW, LV weight; RWT, relative wall thickness; LVEF, LV ejection fraction; LVSF, LV fractional shortening; IVRT isovolumic relaxation time; Mitral E, early diastolic mitral inflow velocities; Mitral A, late diastolic mitral inflow velocities. SHR: SHR treated with vehicle; SHR+AM: SHR treated with Amlodipine; SHR+AT: SHR treated with Atorvastatin; SHR+AM+AT: SHR treated with combination of Amlodipine and Atorvastatin

\begin{tabular}{llllll}
\hline & WKY & SHR & SHR+AM & SHR+AT & SHR+AM+AT \\
\hline LVEDs (cm) & $0.45 \pm 0.03$ & $0.49 \pm 0.06$ & $0.44 \pm 0.05$ & $0.46 \pm 0.07$ & $0.43 \pm 0.03$ \\
LVEDd (cm) & $0.78 \pm 0.03$ & $0.82 \pm 0.04$ & $0.74 \pm 0.04$ & $0.79 \pm 0.09$ & $0.74 \pm 0.05$ \\
IVSd (cm) & $0.16 \pm 0.01$ & $0.19 \pm 0.02$ & $0.18 \pm 0.03$ & $019 \pm 0.03$ & $0.17 \pm 0.04$ \\
LVPWd (cm) & $0.14 \pm 0.03^{* \#}$ & $0.21 \pm 0.02$ & $0.19 \pm 0.04$ & $0.18 \pm 0.03$ & $0.17 \pm 0.02$ \\
LVW (g) & $0.78 \pm 0.06^{* \#}$ & $1.15 \pm 0.12$ & $0.98 \pm 0.11^{* \#}$ & $1.02 \pm 0.12^{* \#}$ & $0.89 \pm 0.08^{*}$ \\
RWT & $0.37 \pm 0.06^{* \#}$ & $0.49 \pm 0.05$ & $0.49 \pm 0.07$ & $0.48 \pm 0.04$ & $0.46 \pm 0.05$ \\
LVEF (\%) & $80.3 \pm 5.2$ & $77.2 \pm 6.4$ & $78.5 \pm 5.4$ & $81.4 \pm 3.9$ & $80.1 \pm 4.3$ \\
LVSF (\%) & $42.3 \pm 3.4$ & $38.9 \pm 5.2$ & $42.4 \pm 5.1$ & $41.9 \pm 3.4$ & $41.8 \pm 3.9$ \\
IVRT (ms) & $27.1 \pm 6.2^{*}$ & $40.3 \pm 4.7$ & $34.2 \pm 6.3$ & $37.1 \pm 4.6 \#$ & $29.8 \pm 3.5^{*}$ \\
Mitral E (cm/s) & $73.3 \pm 11.1$ & $74.2 \pm 16.4$ & $74.5 \pm 9.7$ & $75.4 \pm 12.9$ & $75.1 \pm 14.2$ \\
Mitral A (cm/s) & $61.2 \pm 9.4$ & $67.2 \pm 13.4$ & $64.8 \pm 11.2$ & $64.4 \pm 9.9$ & $63.1 \pm 10.8$ \\
E/A ratio & $1.25 \pm 0.35$ & $1.19 \pm 0.44$ & $1.23 \pm 0.38$ & $1.26 \pm 0.46$ & $1.30 \pm 0.43$ \\
Tei index & $0.52 \pm 0.09$ & $0.57 \pm 0.08$ & $0.55 \pm 0.09$ & $0.59 \pm 0.12$ & $0.57 \pm 0.09$ \\
\hline
\end{tabular}

Echocardiographic analysis

As shown in Table 2, there was no significant difference in LVEDd, LVEDs, IVSd among WKY group, SHR control group and each drug treatment group $(\mathrm{P}>0.05)$. The LVPWd of SHR control group and RWT were significantly higher than those of WKY rats $(\mathrm{P}<0.05)$, but no significant difference among different SHR groups $(P>0.05)$. At 48 weeks old, LVW of SHR control group was significantly higher than that of WKY rats $(P<0.05)$. LVWs of Amlodipine group and Atorvastatin group were significantly decreased than that of SHR control group (P $<0.05$ in all), and LVW of the combination group was decreased even further $(\mathrm{P}<0.05)$. There 


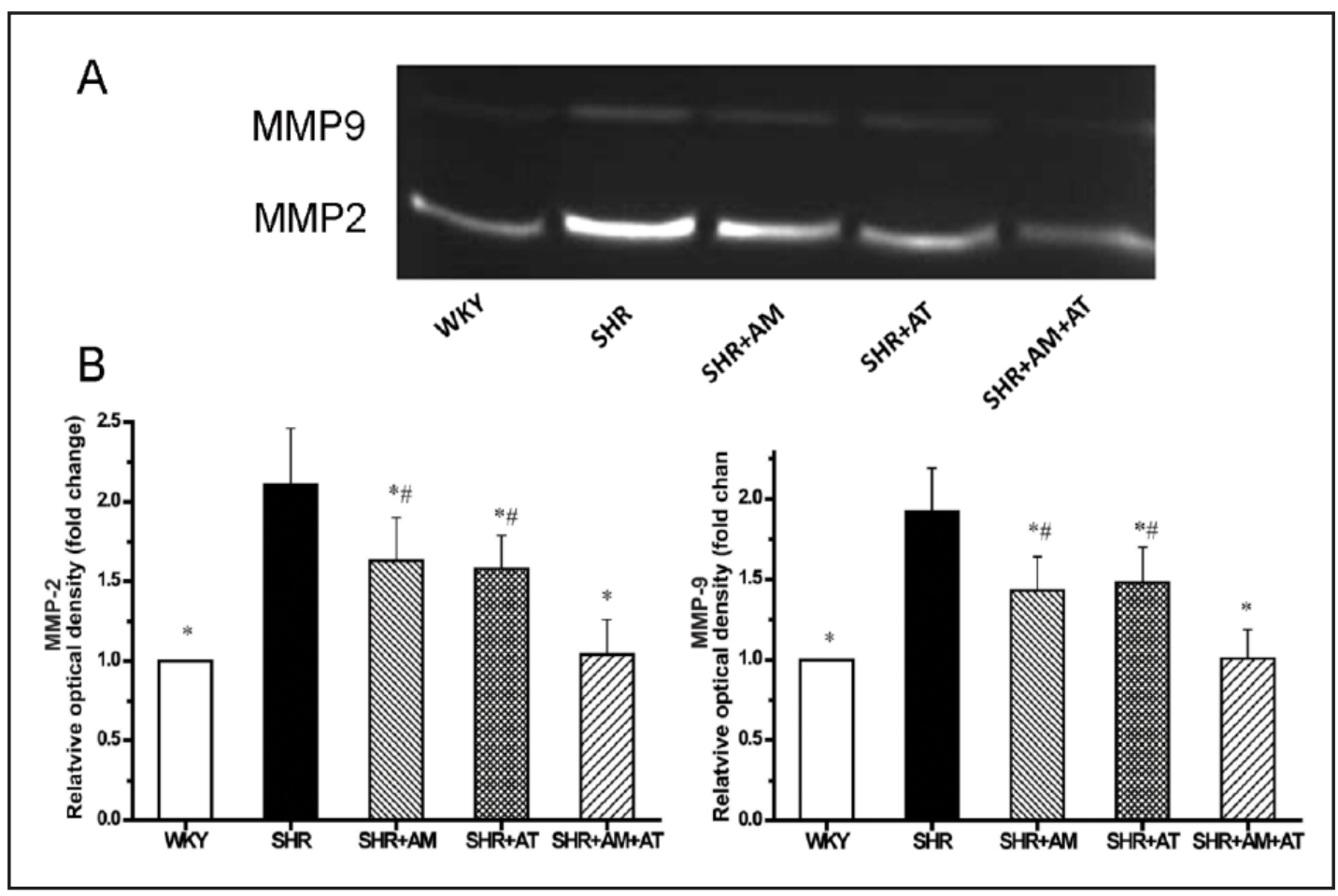

Fig. 2. Effects of Amlodipine, Atorvastatin, and their combination on the activity of MMP-2, MMP-9 in SHR heart. (A) Representative results of Gelatin zymography. (B) Densitometry analysis of Gelatin zymography for MMP-2, MMP-9.Data are expressed as mean \pm SD $(n=5)$. ${ }^{*} P<0.05$ compared with SHR; ${ }^{*}<0.05$ compared with SHR+AM+AT.

were no difference in LVEF, LVFS, and Tei index among all groups ( $\mathrm{P}>0.05)$, suggesting that cardiac systolic function and global function were normal. There were no difference in mitral E wave, A wave, E/A ratio, and Tei index among all groups ( $\mathrm{P}>0.05)$. However, compared to that of WKY rats, IVRT of 48-week-old SHR control group rats was significantly longer $(\mathrm{P}<$ 0.05), indicating that left ventricular diastolic dysfunction was impaired. After Amlodipine or Atorvastatin treatment, IVRT had a tendency to decrease, but there was no significant difference ( $\mathrm{P}>0.05)$, however combination of Amlodipine and Atorvastatin administration could significantly decrease IVRT $(\mathrm{P}<0.05)$.

Effect of Amlodipine, Atorvastatin and combination treatment on MMP-2 and MMP-9 enzyme activity in SHR myocardial tissue

As shown in zymography study (Fig. 2), compared with those of WKY rats, MMP2 and MMP-9 activity in SHR myocardial tissue was significantly increased $(\mathrm{P}<0.05$ for both comparisons). Amlodipine or (and) Atorvastatin intervention significantly decreased MMP-2 and MMP-9 activity ( $<<0.05)$, and the combination of Amlodipine and Atorvastatin treatment lowered MMP-2 and MMP-9 activity significantly more compared with that of monotherapy, which indicated that Amlodipine and Atorvastatin have additive effects on inhibition of MMP activity.

Effect of Amlodipine, Atorvastatin and combination treatment on protein levels of MMP-2, MMP-9, TIMP-1 and TIMP-2 in SHR myocardial tissue

As shown in Fig. 3, Western Blot results showed compared with those of WKY rats, protein levels of MMP-2, MMP-9 and TIMP-1 in SHR myocardial tissue were significantly increased $(\mathrm{P}<0.05$ for both comparisons), however, there was no significant difference in TIMP-2 protein level. Amlodipine or (and) Atorvastatin intervention significantly decreased MMP-2 and MMP-9 protein level $(\mathrm{P}<0.05)$, and the combination of Amlodipine 


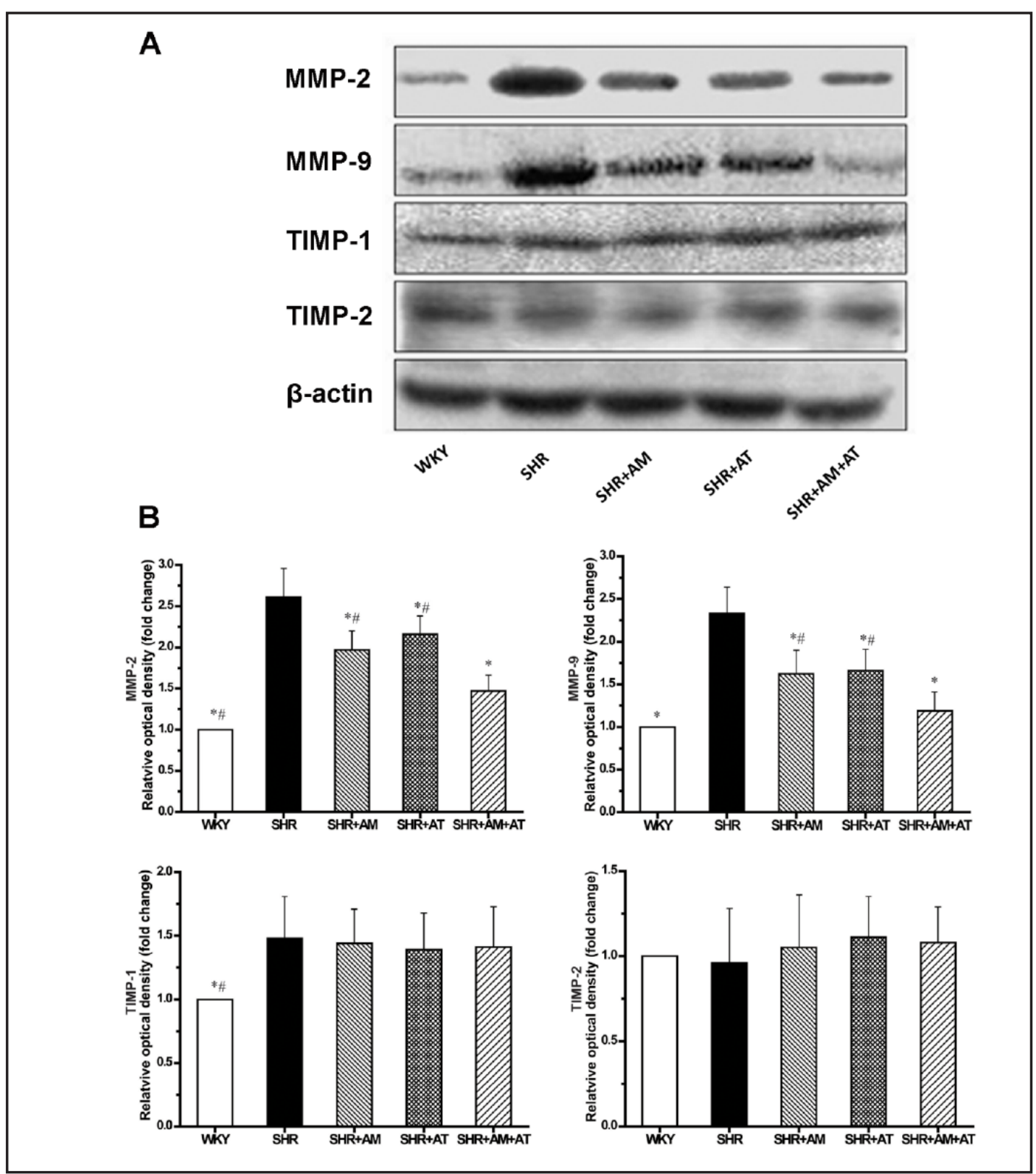

Fig. 3. Effects of Amlodipine, Atorvastatin, and their combination on protein expression of MMP-2, MMP9, TIMP-1 and TIMP-2 in SHR heart. (A) Representative results of Western blot analysis. (B) Densitometry analysis of Western blot for MMP-2, MMP-9, TIMP-1 and TIMP-2.Protein levels in individual samples were normalized to $\beta$-actin protein levels. Data are expressed as mean $\pm \operatorname{SD}(n=5)$. ${ }^{*}<0.05$ compared with SHR; ${ }^{\#} P<0.05$ compared with SHR+AM+AT.

and Atorvastatin treatment lowered MMP-2 and MMP-9 protein level significantly more compared with that of monotherapy, which indicated that Amlodipine and Atorvastatin have additive effects on inhibition of MMP protein expression. However, neither Amlodipine nor Atorvastatin or combination could significantly inhibit TIMP-1 or TIMP-2 expression.

Effect of Amlodipine, Atorvastatin and combination treatment on mRNA levels of MMP-2, MMP-9, TIMP-1 and TIMP-2 in SHR myocardial tissue

As shown in Fig. 4, RT-PCR results showed mRNA levels of MMP-2, MMP-9 and TIMP-1 in SHR myocardial tissue were significantly increased compared with those of WKY rats, 


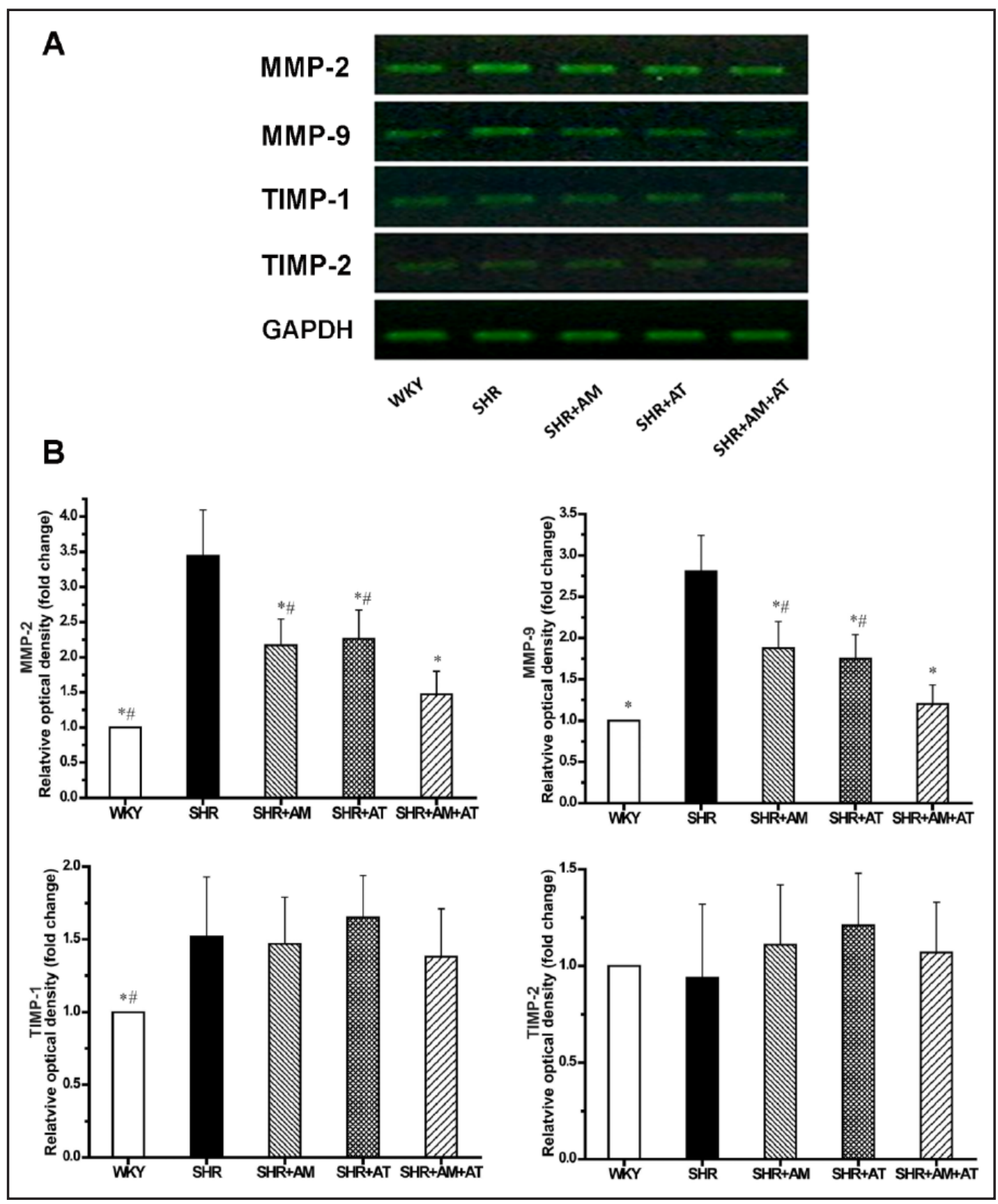

Fig. 4. Effects of Amlodipine, Atorvastatin, and their combination on mRNA expression of MMP-2, MMP-9, TIMP-1 and TIMP-2 in SHR heart. (A) Representative results of RT-PCR analysis. (B) Densitometry analysis of RT-PCR for MMP-2, MMP-9, TIMP-1 and TIMP-2. The mRNA levels in individual samples were normalized to GAPDH mRNA levels. Data are expressed as mean \pm SD $(n=5) .{ }^{*} P<0.05$ compared with SHR; ${ }^{\#}<0.05$ compared with $\mathrm{SHR}+\mathrm{AM}+\mathrm{AT}$.

( $\mathrm{P}<0.05$ for each comparisons), however, there was no significant difference in TIMP-2 mRNA level. Amlodipine or (and) Atorvastatin intervention significantly decreased MMP2 and MMP-9 mRNA level ( $<<0.05)$, and the combination of Amlodipine and Atorvastatin treatment lowered MMP-2 and MMP-9 mRNA level significantly more compared with that of monotherapy, which indicated that Amlodipine and Atorvastatin have additive effects 


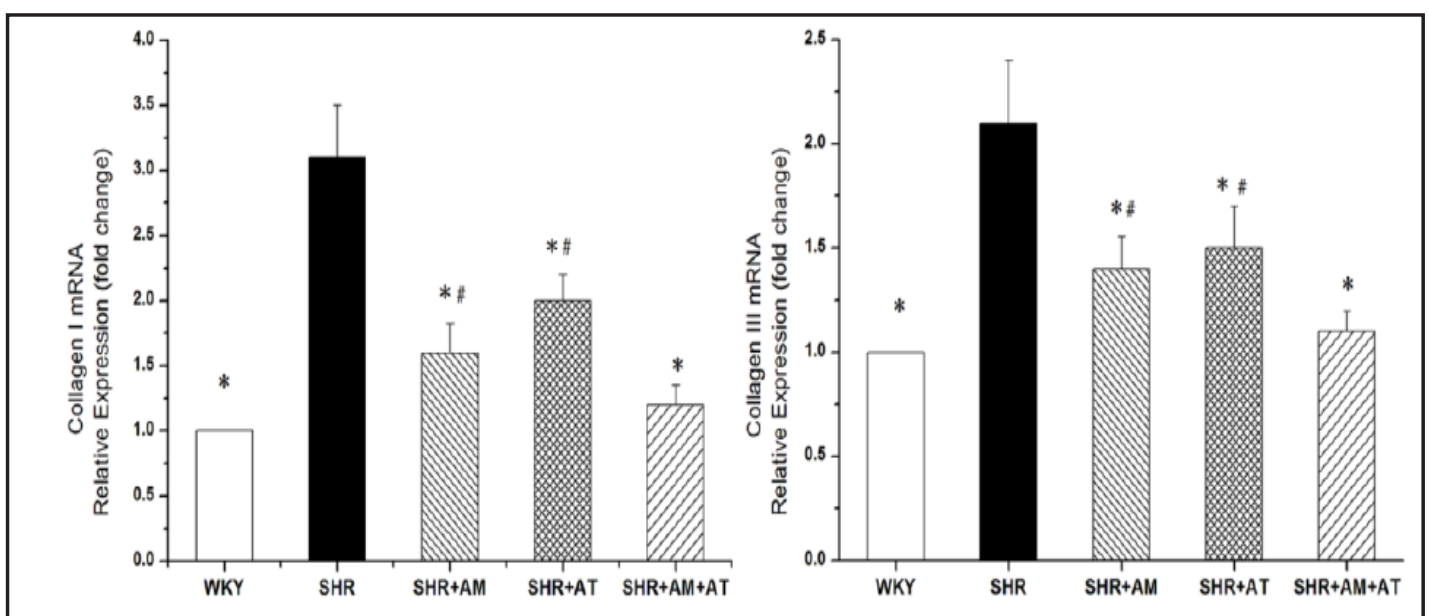

Fig. 5. Effects of Amlodipine, Atorvastatin, and their combination on mRNA expression of type I and III collagen in SHR heart. (A) Representative results of qRT-PCR for type I collagen. (B) Representative results of qRT-PCR for type III collagen. The fold change in expression of each gene was calculated using the $\Delta \Delta \mathrm{Ct}$ method, with the housekeeping gene GAPDH used as an internal control. * $P<0.05$ compared with SHR; ${ }^{\#} P<0.05$ compared with SHR+AM+AT.

on inhibition of MMP at mRNA level. However, neither Amlodipine nor Atorvastatin or combination could significantly inhibit TIMP-1 or TIMP-2 at mRNA level.

Effect of Amlodipine, Atorvastatin and combination treatment on mRNA levels of type I and II collagen

As shown in Fig. 5, quantitative RT-PCR results showed mRNA levels of type I and III collagen in SHR myocardial tissue were significantly increased compared with those of WKY rats, $(\mathrm{P}<0.05$ for each comparisons), however, the mRNA levels of both collagens were significantly inhibited by either Amlodipine or Atorvastatin treatment, with the combination showing an synergistic effects.

\section{Discussion}

Amlodipine and Atorvastatin have been widely used in the treatment of hypertension and hyperlipidemia, and whether either single regimen or combination can prevent or reverse the development of hypertensive heart failure has been a hotspot for research in this field. For example, it has been reported that Atorvastatin could protect vascular smooth muscle cells [15]. But the exact mechanism is still not clear.

The results of this study showed that, compared with those of WKY rats, the mRNA and protein levels of MMP-2 and MMP-9 were significantly increased in the myocardial tissue of SHR rat, and their activities were also enhanced; while the mRNA and protein level of TIMP1 were slightly increased, and there was no difference in TIMP-2 mRNA and protein level. After treatment with Amlodipine, Atorvastatin and combination, mRNA, protein expression and enzyme activity of MMP-2 and MMP-9 were significantly inhibited, with the best result shown with the combination treatment. However, treatment with Amlodipine, Atorvastatin and combination had no effect on the expression of TIMP-1 and TIMP-2 in the myocardial tissue of SHR rats. The results suggest that on the basis of Amlodipine treatment, the addition of Atorvastatin could suppress the expression and activity of MMP- 2 and MMP-9 further, regulate the imbalance of MMP-2 / TIMP-2 and MMP-9/TIMP-1 and improve cardiac matrix remodeling.

MMPs belong to a family of $\mathrm{Zn}^{2+}$ dependent endopeptidase family, in the heart they were mainly secreted by cardiac fibroblasts, cardiomyocytes and inflammatory cells. There are 


\section{Cellular Physiology Cell Physiol Biochem 2016;39:47-60 \\ \begin{tabular}{l|l|l} 
and BiOChemistry & $\begin{array}{l}\text { DOI: 10.1159/000445604 } \\
\text { Published online: June 20, } 2016\end{array}$ & $\begin{array}{l}\text { C } 2016 \text { The Author(s). Published by S. Karger AG, Basel } \\
\text { www.karger.com/cpb }\end{array}$
\end{tabular} \\ Lu et al.: Amlodipine and Atorvastatin Improved Hypertensive Cardiac Remodeling}

over twenty members of MMP family, including collagenase (MMP-1, MMP-8, and MMP-13), gelatinase (MMP-2, MMP-9), matrilysin (MMP-3, MMP-7) and membrane-type MMP (MMP16). TIMP binds to MMP in 1:1 ratio and inhibits its activity. It was reported that not all, but only certain type of MMPs participated in pressure overload-induced cardiac fibrosis and heart failure [16]. For example, it was postulated after a systematic review and metaanalysis that MMP-2, MMP-9 and TIMP-1 may have a role as biomarkers of cardiovascular remodeling in hypertension [17]. Previous studies have found that hypertensive myocardial fibrosis was accompanied by decreased MMP-1 activity and enhanced inhibitory activity of TIMP-1 [18], and the extent of left ventricular fibrosis in MMP-1 overexpression rat after aortic coarctation was significantly lower than that of wild-type mice [19]. In addition, Iwanaga et al. [3] reported that, with the progress of left ventricular hypertrophy, the expression of MMP-2, TIMP-1 and TIMP-2 were increased in myocardial tissue of saltsensitive hypertensive rats. Mujumdar et al. [20] reported that MMP-2 expression and activity were increased in myocardium of 32-week-old SHR rat, which was correlated with diastolic function impairment. Studies on transgenic animals have further revealed a direct role of MMP-2 and MMP-9 on cardiac matrix remodeling. Compared with that of wild-type C57BL/6J mice undergoing aortic coarctation, MMP-2 knockout mice undergoing aortic coarctation had reduced left ventricular mass index, decreased left ventricular end-diastolic pressure, alleviated cardiac hypertrophy and cardiac interstitial fibrosis [4]. On the other hand, studies on the MMP-2 overexpression mouse showed myocardial hypertrophy, broken $\mathrm{Z}$ filaments, degradation of muscle filament, sarcomeres and mitochondria, proliferation of cardiac fibroblasts and myocardial fibrosis in four-month-old MMP-2 transgenic mice [6]. This abnormality increases with age and eventually leading to heart failure. In addition, studies on MMP-9 knockout mice showed that, compared to wild type mice, MMP-9 knockout mice had decreased left ventricular mass, alleviated myocardial hypertrophy and myocardial interstitial fibrosis after aorta coarctation surgery [5]. Clinical data showed that blood MMP9 level in hypertensive patients with left ventricular hypertrophy was significantly higher than those without left ventricular hypertrophy [21].

MMPs, especially MMP-2 and MMP-9 can not only degrade cardiac matrix, but also promote collagen synthesis in cardiac fibroblasts [2, 4, 21]. MMPs can stimulate the release of a variety of cytokines that are related to cardiac matrix, such as TGF- $\beta$, bFGF, PDGF, etc., thereby promoting the synthesis of collagen. On the other hand, after collagen I and III in myocardial interstitium are degraded to terminal macromolecular peptide, MMP-1, MMP-2 and MMP-9 can further cleave terminal macromolecules peptide into Martrikines. Martrikines, which is a matrix degradation product, not only promote collagen synthesis in fibroblasts but also promotes the synthesis and secretion of MMP-2 in fibroblasts, suggesting the mutual promotion role of Martrikines and MMP-2. In summary, it is currently accepted that the enhanced expression and activity of MMP-2 and MMP-9 are important factors in promoting hypertensive myocardial interstitial fibrosis. And consistent with previous reports [20], our results also showed that the expression of MMP-2 and MMP-9 in the myocardial tissue in 48-week-old SHR rats was increased, the activity was also enhanced; and the mRNA and protein levels of TIMP-1 were only slightly increased, while there was no significant change in mRNA and protein level of TIMP-2, suggesting that there exists a local imbalance of MMP-2/TIMP-2 and MMP-9/TIMP-1 in SHR myocardial tissue, thereby promoting myocardial matrix degradation and interstitial fibrosis. Accompanied with the elevated mRNA levels of MMP-2 and MMP-9, the mRNA levels of type I collagen and type III collagen were also increased in the myocardial tissue of 48-week-old SHR rats.

In hypertension, a variety of factors can contribute to the increased synthesis and secretion of MMP-2 and MMP-9 in heart fibroblasts and myocardial cells, such as increases of cardiac mechanical stretch stress induced by pressure overload, Ang II, ROS, inflammatory cytokines TNF - $\alpha$ and IL-1 $\beta$, ET-1, etc. [22-24]. A protective effect of angiotensin-(1-7) against cardiac hypertrophy and collagen deposition has been reported, which may be related to concerted changes in MMPs and TIMPs levels [25]. Our previous study has confirmed that the levels of Ang II, ROS and pro-inflammatory cytokines were increased in myocardium of 
elderly SHR rat [7]. So, as the downstream factors of Ang II, ROS, pro-inflammatory cytokines TNF- $\alpha$ and IL-1 $\beta$, the enhanced expression of MMP- 2 and MMP-9 shown in this study may be related to the upregulated expression of Ang II, ROS and inflammatory cytokines. Since it was shown that Amlodipine and/or Atorvastatin could downregulate ROS levels and inhibit the expression of TNF- $\alpha$ and IL-1 $\beta$ in myocardial tissue, then Amlodipine and/or Atorvastatin could possibly indirectly inhibit the expression and activation of MMP-2 and MMP-9 through intervention with these factors upstream of MMPs/TIMPs system. On the other hand, in vitro studies showed that Amlodipine may decrease mRNA and protein expression and activity of MMP-2 in serum starved rat cardiac fibroblasts through protein kinase pathway [11], and Simvastatin can inhibit TNF- $\alpha$-induced MMP-9 mRNA expression and activity in human heart myofibroblasts [26]; it is also reported that Atorvastatin could inhibit myocardial fibrosis in post-myocardial infarction heart failure by increasing MMP-2/TIMP-2 ration [27], therefore it is also possible that Amlodipine and Atorvastatin can directly inhibit the expression and activity of MMP-2 and MMP-9. To further clarify the effects of Amlodipine and Atorvastatin on myocardial collagen expression, a real-time quantitative PCR method was used to examine the mRNA levels for type I and type III collagen. The results directly showed that both Amlodipine and Atorvastatin could reduce hypertensive cardiac remodeling by inhibiting the synthesis of type I and type III collagen in rats with diastolic dysfunction.

Finally, it has been found that cardiac function varies with age in SHR rats [28, 29], and the reason we chose 36-week-old SHR rats in our study is that the cardiac functions in SHR rats at this age simulated those of elderly hypertensive patients, i.e., chronic hypertension in this age group of patients has led to left ventricular hypertrophy and diastolic dysfunction $[30,31]$.The blood pressure of SHR rats starts to rise at 6-8 weeks after birth; compensatory ventricular hypertrophy starts to develop at 16-18 weeks after birth; diastolic dysfunction begins to appear at about 36 weeks after birth, while systolic function remains in the normal range; and decompensated ventricular hypertrophy started to develop at 70 weeks after birth, with significant dilation of the ventricular cavity and significant decrease of systolic and diastolic function.

In summary, Amlodipine and Atorvastatin inhibited the mRNA, protein expression and activity of MMP-2 and MMP-9 in SHR cardiomyocytes, with the best effect shown with the combination therapy. Amlodipine and/or Atorvastatin treatment can rescue the imbalance of MMP-2/TIMP-2 and MMP-9/TIMP-1 system which is an important mechanism in improving hypertension induced interstitial fibrosis in rat.

\section{Disclosure Statement}

The authors declared that there is no conflict of interests.

\section{References}

1 Segura AM, Frazier OH, Buja LM: Fibrosis and heart failure. Heart Fail Rev 2014;19:173-185.

2 Lopez B, Gonzalez A, Diez J: Role of matrix metalloproteinases in hypertension-associated cardiac fibrosis. Curr Opin Nephrol Hypertens 2004;13:197-204.

3 Iwanaga Y, Aoyama T, Kihara Y, Onozawa Y, Yoneda T, Sasayama S: Excessive activation of matrix metalloproteinases coincides with left ventricular remodeling during transition from hypertrophy to heart failure in hypertensive rats. J Am Coll Cardiol 2002;39:1384-1391.

4 Matsusaka H, Ide T, Matsushima S, Ikeuchi M, Kubota T, Sunagawa K, Kinugawa S, Tsutsui H: Targeted deletion of matrix metalloproteinase 2 ameliorates myocardial remodeling in mice with chronic pressure overload. Hypertension 2006;47:711-717.

5 Heymans S, Lupu F, Terclavers S, Vanwetswinkel B, Herbert JM, Baker A, Collen D, Carmeliet P, Moons L: Loss or inhibition of uPA or MMP-9 attenuates LV remodeling and dysfunction after acute pressure overload in mice. Am J Pathol 2005;166:15-25. 


\section{Cellular Physiology Cell Physiol Biochem 2016;39:47-60 and Biochemistry Published online: June 20, $2016 \quad \begin{aligned} & \text { DOI: 10.1159/000445604 } 2016 \text { The Author(s). Published by S. Karger AG, Basel } \\ & \text { www.karger.com/cpb }\end{aligned}$}

Lu et al.: Amlodipine and Atorvastatin Improved Hypertensive Cardiac Remodeling

6 Zavadzkas JA, Plyler RA, Bouges S, Koval CN, Rivers WT, Beck CU, Chang EI, Stroud RE, Mukherjee R, Spinale FG: Cardiac-restricted overexpression of extracellular matrix metalloproteinase inducer causes myocardial remodeling and dysfunction in aging mice. Am J Physiol Heart Circ Physiol 2008;295:H1394-1402.

7 Lu JC, Cui W, Zhang HL, Liu F, Han M, Liu DM, Yin HN, Zhang K, Du J: Additive beneficial effects of amlodipine and atorvastatin in reversing advanced cardiac hypertrophy in elderly spontaneously hypertensive rats. Clin Exp Pharmacol Physiol 2009;36:1110-1119.

8 Janssens S, Lijnen HR: What has been learned about the cardiovascular effects of matrix metalloproteinases from mouse models? Cardiovasc Res 2006;69:585-594.

9 Peterson JT, Hallak H, Johnson L, Li H, O'Brien PM, Sliskovic DR, Bocan TM, Coker ML, Etoh T, Spinale FG: Matrix metalloproteinase inhibition attenuates left ventricular remodeling and dysfunction in a rat model of progressive heart failure. Circulation 2001;103:2303-2309.

10 Li H, Simon H, Bocan TM, Peterson JT: MMP/TIMP expression in spontaneously hypertensive heart failure rats: the effect of ACE- and MMP-inhibition. Cardiovasc Res 2000;46:298-306.

11 Yue H, Uzui H, Shimizu H, Nakano A, Mitsuke Y, Ueda T, Lee JD: Different effects of calcium channel blockers on matrix metalloproteinase-2 expression in cultured rat cardiac fibroblasts. J Cardiovasc Pharmacol 2004;44:223-230.

12 Saka M, Obata K, Ichihara S, Cheng XW, Kimata H, Nishizawa T, Noda A, Izawa H, Nagata K, Murohara T, Yokota M: Pitavastatin improves cardiac function and survival in association with suppression of the myocardial endothelin system in a rat model of hypertensive heart failure. J Cardiovasc Pharmacol 2006;47:770-779.

13 Ichihara S, Noda A, Nagata K, Obata K, Xu J, Ichihara G, Oikawa S, Kawanishi S, Yamada Y, Yokota M: Pravastatin increases survival and suppresses an increase in myocardial matrix metalloproteinase activity in a rat model of heart failure. Cardiovasc Res 2006;69:726-735.

14 Kishida M, Otsuka F, Ogura T, Kataoka H, Nakamura Y, Yamauchi T, Takahashi M, Yokota K, Mimura Y, Makino H: Chronic treatment with amlodipine modulates adrenocortical angiotensin II receptors in spontaneously hypertensive rats. Life Sci 2001;69:113-122.

15 Liu D, Cui W, Liu B, Hu H, Liu J, Xie R, Yang X, Gu G, Zhang J, Zheng H: Atorvastatin protects vascular smooth muscle cells from TGF-beta1-stimulated calcification by inducing autophagy via suppression of the betacatenin pathway. Cell Physiol Biochem 2014;33:129-141.

16 Moore L, Fan D, Basu R, Kandalam V, Kassiri Z: Tissue inhibitor of metalloproteinases (TIMPs) in heart failure. Heart Fail Rev 2012;17:693-706.

17 Marchesi C, Dentali F, Nicolini E, Maresca AM, Tayebjee MH, Franz M, Guasti L, Venco A, Schiffrin EL, Lip GY, Grandi AM: Plasma levels of matrix metalloproteinases and their inhibitors in hypertension: a systematic review and meta-analysis. J Hypertens 2012;30:3-16.

18 Nagatomo Y, Carabello BA, Coker ML, McDermott PJ, Nemoto S, Hamawaki M, Spinale FG: Differential effects of pressure or volume overload on myocardial MMP levels and inhibitory control. Am J Physiol Heart Circ Physiol 2000;278:H151-161.

19 Foronjy RF, Sun J, Lemaitre V, D'Armiento JM: Transgenic expression of matrix metalloproteinase-1 inhibits myocardial fibrosis and prevents the transition to heart failure in a pressure overload mouse model. Hypertens Res 2008;31:725-735.

20 Mujumdar VS, Smiley LM, Tyagi SC: Activation of matrix metalloproteinase dilates and decreases cardiac tensile strength. Int J Cardiol 2001;79:277-286.

21 Ahmed SH, Clark LL, Pennington WR, Webb CS, Bonnema DD, Leonardi AH, McClure CD, Spinale FG, Zile MR: Matrix metalloproteinases/tissue inhibitors of metalloproteinases: relationship between changes in proteolytic determinants of matrix composition and structural, functional, and clinical manifestations of hypertensive heart disease. Circulation 2006;113:2089-2096.

22 Coker ML, Jolly JR, Joffs C, Etoh T, Holder JR, Bond BR, Spinale FG: Matrix metalloproteinase expression and activity in isolated myocytes after neurohormonal stimulation. Am J Physiol Heart Circ Physiol 2001;281:H543-551.

23 Grote K, Flach I, Luchtefeld M, Akin E, Holland SM, Drexler H, Schieffer B: Mechanical stretch enhances mRNA expression and proenzyme release of matrix metalloproteinase-2 (MMP-2) via NAD(P)H oxidasederived reactive oxygen species. Circ Res 2003;92:e80-86.

24 Siwik DA, Pagano PJ, Colucci WS: Oxidative stress regulates collagen synthesis and matrix metalloproteinase activity in cardiac fibroblasts. Am J Physiol Cell Physiol 2001;280:C53-60. 


\section{Cellular Physiology Cell Physiol Biochem 2016;39:47-60 \begin{tabular}{l|l} 
DOI: 10.1159/000445604 & $\begin{array}{l}\text { O 2016 The Author(s). Published by S. Karger AG, Basel } \\
\text { www.karger.com/cpb }\end{array}$
\end{tabular}}

Lu et al.: Amlodipine and Atorvastatin Improved Hypertensive Cardiac Remodeling

25 Pei Z, Meng R, Li G, Yan G, Xu C, Zhuang Z, Ren J, Wu Z: Angiotensin-(1-7) ameliorates myocardial remodeling and interstitial fibrosis in spontaneous hypertension: role of MMPs/TIMPs. Toxicol Lett 2010;199:173-181.

26 Turner NA, Aley PK, Hall KT, Warburton P, Galloway S, Midgley L, O'Regan DJ, Wood IC, Ball SG, Porter KE: Simvastatin inhibits TNFalpha-induced invasion of human cardiac myofibroblasts via both MMP-9dependent and -independent mechanisms. J Mol Cell Cardiol 2007;43:168-176.

27 An Z, Yang G, He YQ Dong N, Ge LL, Li SM, Zhang WQ: Atorvastatin reduces myocardial fibrosis in a rat model with post-myocardial infarction heart failure by increasing the matrix metalloproteinase-2/tissue matrix metalloproteinase inhibitor-2 ratio. Chin Med J (Engl) 2013;126:2149-2156.

28 Pagan LU, Damatto RL, Cezar MD, Lima AR, Bonomo C, Campos DH, Gomes MJ, Martinez PF, Oliveira SA, Jr., Gimenes R, Rosa CM, Guizoni DM, Moukbel YC, Cicogna AC, Okoshi MP, Okoshi K: Long-term low intensity physical exercise attenuates heart failure development in aging spontaneously hypertensive rats. Cell Physiol Biochem 2015;36:61-74.

29 Li L, Zhang W, Shi WY, Ma KT, Zhao L, Wang Y, Zhang L, Li XZ, Zhu H, Zhang ZS, Liu WD, Si JQ: The enhancement of $\mathrm{Cx} 45$ expression and function in renal interlobar artery of spontaneously hypertensive rats at different age. Kidney Blood Press Res 2015;40:52-65.

30 Muders F, Elsner D: Animal models of chronic heart failure. Pharmacol Res 2000;41:605-612.

31 Cingolani OH, Yang XP, Cavasin MA, Carretero OA: Increased systolic performance with diastolic dysfunction in adult spontaneously hypertensive rats. Hypertension 2003;41:249-254. 